\title{
Adverse Reactions in Whole Blood Donors: An Experience in a Tertiary Health Care Centre
}

\author{
Sandhya $\mathrm{M}^{1}$, Purushottam $\mathrm{R}^{2}$, Sowmya $\mathrm{TS}^{2^{*}}$ \\ ${ }^{1}$ Assistant Professor, Department of Pathology, Kodagu Institute of medical sciences, Madikeri, Karnataka, India \\ ${ }^{2}$ Associate Professor, Department of Pathology, Hassan institute of medical sciences, Hassan, Karnataka, India
}

\author{
DOI: $10.36348 /$ sjpm.2020.v05i12.007 \\ | Received: 26.11.2020 | Accepted: 06.12.2020 | Published: 18.12.2020 \\ *Corresponding author: Dr. Sowmya TS
}

\section{Abstract}

Background: In a society to improve medical facilities, one of the crucial parts is the availability of safe and good quality blood. The occurrence of adverse events during blood donation affects donor return. Aims and Objectives: To analyse the frequency and significance of adverse events during blood donation. Materials and Methods: This study was conducted for a period of one and a half years from 1st January 2018 to 30th June 2019 on 11,170 allogenic blood donors including both voluntary and replacement donors. The type and frequency of adverse events were recorded during blood donation. Results: 116 adverse events were recorded resulting in $1 \%$ adverse event rate, among which majority had vasovagal reaction $89(76.7 \%)$, followed by hematoma formation $15(12.9 \%)$, nerve injury $11(9.5 \%)$ and rebleeding at the site of prick $1(0.9 \%)$. Significant relation with female sex, younger age, low weight, donating in camps and first-time donors was noted. Conclusion: In existing scenario of shortage of blood in India, new and existing donors should be motivated to donate blood regularly by bringing down the events of adverse reactions during blood donation.

Keywords: Adverse reactions, blood donation, vasovagal reaction.

Copyright (C) 2020 The Author(s): This is an open-access article distributed under the terms of the Creative Commons Attribution 4.0 International License (CC BY-NC 4.0) which permits unrestricted use, distribution, and reproduction in any medium for non-commercial use provided the original author and source are credited.

\section{INTRODUCTION}

Blood can't be manufactured synthetically and, therefore, donation is required [1]. Lack of awareness and motivation within the community, along with a fragmented transfusion service in our country, often results in scarcity of blood and blood components [2]. Replacement donors, who still form a huge proportion of all blood donors in developing countries, if found non-reactive for transfusion transmissible infection are often retained as voluntary donors in future [3]. Adverse events (AEs) in blood donors can adversely affect donor recruitment and retention. Blood donation is generally considered to be a safe procedure, but occasionally adverse reactions of varying severity may occur at the time of collection in $2-3 \%$ of blood donors $[4,5]$. Usually, these are minor symptoms associated with the donation process. However serious adverse symptoms may rarely occur. Adverse responses to donation can be acute: after single donation or chronic: in response to long-term donation. These

symptoms range from a light vasovagal reaction (VVR), nausea, vomiting, and hyperventilation to hematoma, incontinence, nerve injury, arterial puncture, and may end in delayed syncope, asystole and seizures $[1,6]$.

Donor hemovigilance is a significant aspect of the hemovigilance system and contributes to decrease the donor reactions and improving donor safety and functioning of blood bank. Reporting of adverse reactions related to blood donations has been covered under National donor vigilance programme (NBDVP) [7, 8]. Donor hemovigilance involves collecting and organizing data associated with reactions that occur during the blood donation and information about donor, donation and reaction attributes that potentially influence the reactions. It is the cornerstone for improving donor safety [9]. Donor reaction had the most negative impact on the donor return rate. Mitigation of few adverse events has the potential to improve donor return rate $[6,10]$.

Hence the aim of the present study is to estimate the frequency and type of adverse events occurring during blood donation and to identify any demographic association. 


\section{MATERIALS AND METHODS}

This was a descriptive study conducted in Hassan Institute of Medical Sciences, Hassan, Karnataka on a total of 11,170 allogenic blood donors including both voluntary and replacement donors, those who donate blood in blood bank and in blood donation camps organized at various locations. The study was approved by the institutional ethical committee. The duration of the study was 18 months ranging from $1^{\text {st }}$ January 2018 to $30^{\text {th }}$ June 2019. Prior informed consent of the donors was taken and the donor information confidentiality was assured. All donations were collected using a 16-gauge needle inserted into a vein in the antecubital area. Strict asepsis was maintained by cleaning the site of venepuncture sequentially using savlon, betadine and alcohol. For whole blood donation $350 \mathrm{~mL}$ of whole blood were collected from donors weighing between 45 and $55 \mathrm{~kg}$ while donors weighing more than $55 \mathrm{~kg}$ donated $450 \mathrm{~mL}$ of whole blood. The donors were observed before, during and after blood donation for any adverse event. For delayed adverse reactions, donors were requested to contact the researcher or designated departmental staff. The classification scheme employed for recording the adverse events was suggested by the American Red Cross Hemovigilance Program was followed. Data was analysed using SPSS statistics software. Association between blood donor adverse reaction and age, sex and other criteria were calculated using Chi-square test. A p value $<.05$ was considered significant.

\section{Inclusion Criteria}

Criteria for the selection of whole blood donors in accordance with rules laid down in Drugs and Cosmetics Act, Ministry of Health and Family Welfare, Government of India.

\section{Exclusion Criteria}

Adverse reaction was defined as the symptoms or signs of donor discomfort of sufficient severity such that either the donor called the attention of the staff or they were noticed by the staff. Pain at the time of venepuncture was excluded.

\section{RESULTS}

During the study period a total of 11,170 donors donated blood, out of which 9268(83\%) were voluntary donors and 1902(17\%) were replacement donors. 87 blood donation camps were done at various places outside blood bank in the duration of 18 months. In blood bank 7699 (68.9\%) donated blood whereas $3471(31.1 \%)$ donated in camps. There were $895(8.1 \%)$ female donors and $10275(91.9 \%)$ male donors, who formed the majority. The mean age was $28.0 \pm 6.4$ years and the mean weight was $64.5 \pm 8.4 \mathrm{~kg}$. Overall, 116 adverse events were recorded in relation to 11,170 blood donations, resulting in $1 \%$ adverse event rate.

There was a significant relation with $\mathrm{p}$ value $<0.00001$ between adverse events and gender. Among
116 donors in whom adverse events were recorded, 82 $(70.7 \%)$ were females and $34(29.3 \%)$ were males.

Majority of the adverse events were observed in the age group ranging from 18-40 years i.e. 75 $(64.7 \%)$. Remaining $41(35.3 \%)$ donors in whom adverse events were seen belonged to 41-60 years age group. Thus, a significant $\mathrm{p}$ value of $<0.00001$ was seen between age group and adverse events.

In 116 adverse events, $64(55.1 \%)$ donors were in the $45-65 \mathrm{kgs}$ group while $52(44.8 \%)$ were in $>65$ $\mathrm{kgs}$ group. A significant $\mathrm{p}$ value of .03 was noted when adverse events and body weight of the blood donors was compared.

Adverse events observed in blood donation camps were high $94(81.1 \%)$ compared to seen in blood bank $22(18.9 \%)$ with significant $p$ value $<0.00001$.

$108(93.1 \%)$ were first time donors and remaining $8(6.9 \%)$ were repeat donors in the 116 adverse events observed. A significant $p$ value of .0027 was noted.

According to the American Red Cross Hemovigilance Program, the adverse events were recorded. Among 116 adverse events, 89 (76.7\%) donors had vasovagal reaction forming the most common adverse event. Out of them donors with loss of consciousness less than 60 seconds were 81 (69.8\%) and loss of consciousness more than a minute were 08 $(6.9 \%)$. Other symptoms seen in vasovagal reaction were perspiration, pallor, nausea, vomiting, palpitations, weakness, thirst, chest tightness, cramps, bladder/ bowel incontinence, tremors and seizures.

This was followed by hematoma formation in $15(12.9 \%)$ donors. Nerve injury with numbness and tingling was seen in $11(9.5 \%)$ and $1(0.9 \%)$ donor had an incidence of rebleeding at the site of prick. No cases of arterial puncture, local inflammation (cellulitis, thrombophlebitis), major blood vessel injury (deep vein thrombosis, arterio-venous fistula, compartment syndrome), allergic reaction (local, generalised) or serious complication (cardiac arrest, cerebrovascular accident) was seen.

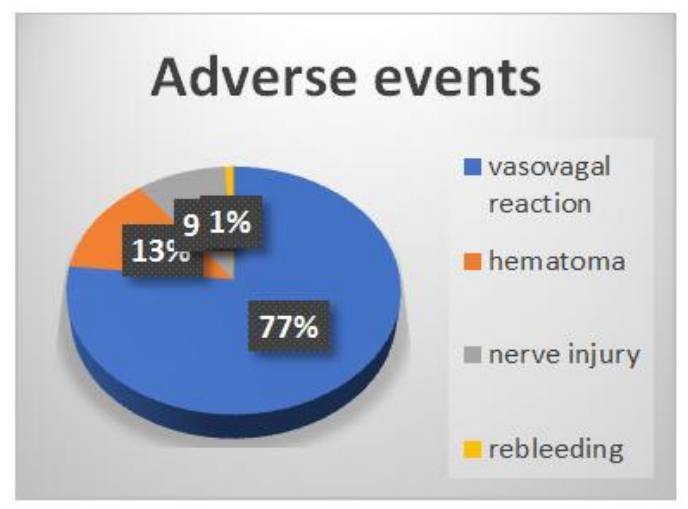

Fig-1: Adverse events 
Table-1: Adverse events $(n=116 / 11170)$

\begin{tabular}{|l|l|l|l|}
\hline \multicolumn{2}{|l|}{ PARAMETERS } & \multicolumn{2}{l|}{ ADVERSE EVENTS } \\
\hline Gender & Male & 34 & $29.3 \%$ \\
\hline & Female & 82 & $70.7 \%$ \\
\hline Age & $18-40$ years & 75 & $64.7 \%$ \\
\hline & $40-60$ years & 41 & $35.3 \%$ \\
\hline Weight & $45-65 \mathrm{kgs}$ & 64 & $55.1 \%$ \\
\hline & $>65 \mathrm{kgs}$ & 52 & $44.8 \%$ \\
\hline Site & Camps & 94 & $81.1 \%$ \\
\hline & Blood bank & 22 & $18.9 \%$ \\
\hline Type & First time donors & 108 & $93.1 \%$ \\
\hline & Repeat donors & 8 & $6.9 \%$ \\
\hline
\end{tabular}

\section{DISCUSSION}

In our study we found a low overall adverse events rate $(1 \%)$ which was in concurrence with Sultan S et al., [1] (1.3\%) and Savaliya SM et al., [7] (1.54\%). Few studies showed lower rate- Pathak C et al., [4] $(0.6 \%)$ whereas few studies showed a higher rateAgnihotri $\mathrm{N}$ et al., [2] (2.5\%) and Abhishek et al., [11] $(2.04 \%)$. These disparities may be due to different demographics, conduct of blood collection staff or variation in the information collection methodology from the donors.

In the present study, the occurrence of adverse events was more commonly seen in females, younger age (18-40 years), lower weight (45-65 kgs), blood donation in camps and those who were donating blood for the first time. These findings were in agreement with Agnihotri N et al., [2]. Savaliya SM et al., [7] showed similar results but adverse events were seen more in males and in repeat donors.

We noted that the number of male donors were remarkably high compared to female donors, but the percentage of adverse events occurrence was significantly more in females. This was attributed most likely due to the anxiety regarding needle prick and sight of blood which was expressed by most of the female sex.

The prevalence of adverse events was notably low in older age. A study by France [12] postulated that baroreceptor sensitivity is decreased in healthy young individuals when they are physically or psychologically stressed. With increasing age, the body becomes more stable hemodynamically.

As in most centres, in our setup too volume of blood collected is according to the weight of the individual- $350 \mathrm{ml}$ in less than $55 \mathrm{~kg}$ and $450 \mathrm{ml}$ in more than $55 \mathrm{~kg}$. Yet we observed a significant relationship between weight and reaction rate. A probable reason could be difference in age distribution of donors.

Blood donation camps formed a major influence in donor reaction rate. Blood banks provide comfortable place as per regulatory requirements which relieves most of the stress in the donors. Lack of proper premises and environment may increase the apprehension concerning blood donation, especially in young and first-time donors.

Repeat donor status showed a significant decreased adverse events rate. First time donors are usually young and have less knowledge regarding blood donation procedure. Appropriate counselling prior to donation along with adequate water and nutrition intake reduces the donation reaction rate.

Vasovagal reaction was the most common adverse event observed in the present study (76.7\%). This was in concordance with most of the studiesSultan S et al., [1], Agnihotri N et al., [2], Kumari S [6] and Savaliya SM et al., [7]. Vasovagal reaction can be triggered by the pain of the venipuncture, by the donor seeing one's own blood, by seeing another donor unwell or by the anxiety and state of tension of undergoing the donation.

The long-term complications were rare in our study due to under-reporting of the events as it required the donors to call back the researcher.

\section{CONCLUSION}

Blood banks have a dual responsibility: to meet the blood and its components supply to the community and to assure blood donors' safety. One of the essential prerequisites to ensure donor return is to create physical and mental well-being of the donor. This will help to achieve the $100 \%$ voluntary donation objective of National Blood Policy, which is at present $61 \%$ in our country [13].

Our study helps in identifying the risk factors for adverse events and plan population-based strategies that focus on safety of donors. This will improve recruitment and retaining the voluntary blood donors.

\section{Conflict of interest: Nil}

\section{REFERENCES}

1. Sultan, S., Baig, M. A., Irfan, S. M., Ahmed, S. I., \& Hasan, S. F. (2016). Adverse reactions in 
allogeneic blood donors: A tertiary care experience from a developing country. Oman Medical Journal, 31(2), 124-128.

2. Agnihotri, N., Marwaha, N., \& Sharma, R. R. (2012). Analysis of adverse events and predisposing factors in voluntary and replacement whole blood donors: A study from north India. Asian journal of transfusion science, 6(2), 155-160.

3. World Health Organization. (2008). Blood safety and donation. [Last cited 2010 Dec 10]. Available from:

http://www.who.int/mediacentre/factsheets/fs279/ en.

4. Pathak, C., Pujani, M., Pahuja, S., \& Jain, M. (2011). Adverse reactions in whole blood donors: an Indian scenario. Blood Transfusion, 9(1), 46.

5. Bisht, A., Singh, S., \& Marwaha, N. (2016). National blood donor vigilance programme: India. Asian journal of transfusion science, 10(1), 1.

6. Kumari, S. (2015). Prevalence of acute adverse reactions among whole blood donors: A 7 years study. Journal of Applied Hematology, 6(4), 148153.

7. Savaliya, S. M., Singh, A. P., \& Piparva, K. G. (2019). A donor hemovigilance study: evaluation of adverse reactions to blood donors at tertiary care teaching hospital. International Journal of Basic \& Clinical Pharmacology, 8(7), 1538-1541.
8. Bisht, A., Singh, S., \& Marwaha, N. (2016). National blood donor vigilance programme: India. Asian journal of transfusion science, 10(1):1-2.

9. Erraguntla, M., Tomasulo, P., Land, K., Kamel, H., Bravo, M., Whitaker, B., ... \& Khaire, S. (2014, January). Data Mining to Improve Safety of Blood Donation Process. In 2014 47th Hawaii International Conference on System Sciences (pp. 789-795). IEEE.

10. Newman, B. H., Newman, D. T., Ahmad, R., \& Roth, A. J. (2006). The effect of whole- blood donor adverse events on blood donor return rates. Transfusion, 46(8), 1374-1379.

11. Abhishekh, B., Mayadevi, S., \& Usha, K. C. (2013). Adverse reactions to blood donation. Innovative Journal of Medical and Health Science, 3(4), 158-160.

12. France, C. (1995). Baroreflex sensitivity during noxious stimulation in vasovagal reactors to blood donation. Int J Psychophysiol. 19:13-22.

13. National Blood Policy. (2007). Objective-1: To reiterate firmly the Govt. commitment to provide safe and adequate quantity of blood, blood components and blood products. National AIDS Control Organization. Ministry of Health and Family Welfare. Govt. of India. [Last accessed on 2010 Dec 12]. pp. 7-8. Available from:http://www.nacoonline.org/upload/Final\%20 Publications/Blood\%20Safety/National\%20Blood \%20Policy.pdf 